\title{
EDUCAÇÃO EM CIÊNCIAS E EDUCAÇÃO DE JOVENS E ADULTOS: PELA NECESSIDADE DO DIÁLOGO ENTRE CAMPOS E PRÁTICAS*
}

\author{
Science education, youth, and adult education: \\ the necessity of dialogue between fields and practices
}

Rita Vilanova ${ }^{1}$

Isabel Martins ${ }^{2}$

\begin{abstract}
Resumo: Neste trabalho buscamos entender as articulações entre a Educação em Ciências e a Educação de Jovens e Adultos (EJA) no contexto de mudanças na legislação que demandaram uma necessidade de diálogo entre estes campos da educação. Para tanto foi realizada a análise de um material que subsidia a elaboração de propostas curriculares de Ciências para a EJA em âmbito nacional. Esta foi realizada sob a perspectiva da análise crítica do discurso, em que textos são considerados um produto histórico e social, e, desta forma, heterogêneos. Neste sentido, os objetivos deste trabalho relacionam-se com o entendimento de como o discurso da EJA e o da Educação em Ciências dialogam na construção deste material. Nossos resultados indicam que a proposta curricular para a EJA representa em muitos aspectos o discurso dos Parâmetros Curriculares Nacionais, o que reflete o caráter incipiente da discussão acerca da Educação em Ciências para jovens e adultos e indica uma identidade institucional em construção.

Palavras-chave: Educação em Ciências. Educação de jovens e adultos. Proposta curricular. Análise crítica do discurso.
\end{abstract}

\begin{abstract}
This paper aims at understanding the connections between Science Education and Youth and Adult Education (EJA) in the context of Brazilian legislative changes, which stressed the need for dialogue between these educational fields. Documents issued by the government containing recommendations for the elaboration of EJA science curricula at national level were analyzed using Critical Discourse Analysis in order to understand how both EJA and Science Education discourses engage in a dialogue in the construction of this text. Intertextual analyses led to results that indicate that the government's document for EJA represents, in many aspects, the discourse of the National Curricular Parameters, which reflects the tentative character of the discussions about science education for young people and adults and indicates an institutional identity under construction.
\end{abstract}

Keywords: Science teaching. Young people and adult education. Science curriculum. Critical discourse analysis.

\footnotetext{
*Elaborado com base em apresentação realizada no V Encontro Nacional de Pesquisa em Educação em Ciências (V ENPEC), realizado em Bauru-SP, em dezembro de 2005. Apoio CNPq.

${ }^{1}$ Programa de Pós-Graduação em Educação em Ciências e Saúde, Núcleo de Tecnologia Educacional para a Saúde (NUTES), Universidade Federal do Rio de Janeiro (UFRJ). < vilanovar@terra.com.br>

2 Programa de Pós-Graduação Educação em Ciências e Saúde, NUTES/UFRJ. <isabelmartins@ufrj.br>

${ }^{1}$ UFRJ - Centro de Ciências da Saúde, Bloco A - Sala 26

Cidade Universitária - Ilha do Fundão

Rio de Janeiro, RJ

$21.941-902$ 


\section{Motivações e objetivos}

Nas últimas décadas, a educação de jovens e adultos (EJA) vem se configurando como um campo pedagógico comprometido com o desenvolvimento de reflexões críticas sobre suas necessidades e objetivos, e buscando compreender seus educandos e seus professores. Entretanto, no que tange o ensino da disciplina Ciências, poucos esforços vêm sendo feitos no sentido de explicitar ou discutir seus contornos e especificidades neste campo pedagógico. Por sua vez, trabalhos desenvolvidos junto a estudantes jovens e adultos são praticamente inexistentes na literatura do campo da Educação em Ciências (EC); e mesmo trabalhos como os de Barros et al. (2003) e Martins, Nascimento e Abreu (2004), que investigam concepções de professores, leituras realizadas por alunos e interações discursivas nesta modalidade de ensino, não problematizam sua natureza, suas especificidades e questões. Situação semelhante pôde ser observada na revisão das atas do V Encontro Nacional de Pesquisa em Educação em Ciências (V ENPEC): dos 731 trabalhos inscritos, apenas três eram referentes ao tema Educação em Ciências na EJA. Em conseqüência, questões que dizem respeito aos objetivos e às formas de abordar temas relacionados às ciências naturais junto a grupos de estudantes jovens e adultos permanecem obscuras.

A discussão acerca da educação em ciências para jovens e adultos também não é freqüente em documentos oficiais. Um dos poucos documentos que explicita relações entre estes campos é a Proposta Curricular para a EJA, publicada pela Secretaria de Ensino Fundamental do MEC (BRASIL, 2002). Pelo seu caráter pioneiro na proposição desta discussão e pelo seu papel para subsidiar o desenvolvimento de currículos de ciências para a EJA em âmbito nacional, decidimos analisar o texto da proposta buscando compreender como a interlocução entre estes campos foi realizada nesta proposta, o que nos permite problematizar lacunas, identificar os obstáculos existentes à construção de sentidos entre estas áreas da educação e, ainda, refletir sobre as possibilidades de contribuição entre a EJA e o EC, enquanto espaços de pesquisa e intervenção. O marco teórico-metodológico para esta análise foi a Análise Crítica do Discurso, uma perspectiva que considera o texto como produto histórico e social, e que busca evidenciar seu caráter heterogêneo por meio da caracterização de como outros diferentes textos o atravessam e constituem.

\section{Produção de textos: a abordagem da análise crítica do discurso}

A análise crítica do discurso (FAIRCLOUGH, 2001; KRESS, 1988) representa uma vertente da Análise do Discurso que tem como principais influências: as idéias de Gramsci sobre hegemonia; o conceito de intertextualidade, proposto por Kristeva com base em leituras de Bakhtin; as abordagens da Lingüística Sistêmica Funcional de Halliday, e as contribuições de Foucault para os estudos do discurso. Na perspectiva da análise crítica do discurso (ACD), os eventos discursivos são considerados tridimensionais, ou seja, envolvem simultaneamente textos, práticas sociais e práticas discursivas (FOUCAULT, 1972). Segundo Fairclough (2001, p. 107), "a prática discursiva envolve processos de produção, distribuição e consumo textual e a natureza desses processos varia entre diferentes tipos de discurso de acordo com fatores sociais". 
Para a ACD, as condições para o desenvolvimento de determinada prática discursiva relacionam-se com as práticas sociais de produção e consumo dos textos, associadas ao tipo de discurso que desejamos analisar. Valendo-nos de formas recorrentes em textos e enunciações que se referem à educação de jovens e adultos e à Educação em Ciências relacionadas às suas condições sociais de produção, propomos considerá-las como formações discursivas. Desta forma, nossas análises permitem problematizar relações entre diferentes aspectos específicos de propostas educativas para a EJA e para a Educação em Ciências, tais como: objetivos, características dos sujeitos envolvidos, escolhas envolvidas nas definições de currículos, reformas educacionais, mudanças na legislação, demandas da sociedade e outros.

\section{Intertextualidade}

A Análise Crítica do Discurso considera, a exemplo das abordagens bakhtinianas (BAKHTIN, 2000), que todo texto é constituído por elementos de outros textos. Atualiza e responde a textos que o antecederam, ao mesmo tempo em que orienta-se e antecipa-se a textos que o seguirão. Esta heterogeneidade dos textos incorpora as relações entre as convenções e práticas que estruturam as ordens do discurso (FOUCAULT, 1972), podendo recorrer a elas diretamente ou indiretamente. A análise dos processos de produção textual relaciona-se, portanto, com o entendimento da heterogeneidade do texto, o que implica a análise do mesmo em duas dimensões.

A primeira busca a interdiscursividade (intertextualidade constitutiva) presente no texto, que permite a identificação dos tipos de discurso que o estão constituindo, por meio da análise das configurações de tipos de texto ou de convenções discursivas. Segundo Fairclough, (2001), o conceito de interdiscursividade enfatiza a heterogeneidade dos textos, bem como uma visão histórica destes, ou seja, textos do passado são constantemente transformados em textos do presente. A interdiscursividade pode ser caracterizada por intermédio das atividades, discursos e estilos delineados em um texto. As atividades relacionam-se com o tipo de ação social envolvido na produção do texto, sendo determinadas, desta forma, pelas relações estabelecidas para tal dentro das instituições. Os discursos configuram formas particulares de construção dos textos, no sentido de que enfatizam determinados conteúdos e áreas do conhecimento de maneira bastante arbitrária, de acordo com os interesses institucionais (FAIRCLOUGH, 2001). Os estilos podem ser classificados em categorias que Halliday (1978) chamou de tenor, modo e modo retórico. A dimensão do estilo relaciona-se com a questão de que a linguagem varia de acordo com a situação, ou seja, determina a seleção de significados e as formas que são utilizadas para sua expressão de acordo com o contexto social em que os textos são produzidos. Neste sentido, a categoria tenor está relacionada com o status e o papel das relações estabelecidas no texto, ou seja, é determinado pelas redes de comunicação formadas pelos diferentes grupos sociais. O modo é determinado pelas estratégias e escolhas da linguagem utilizada de acordo com a situação, ou seja, com o canal de comunicação adotado (HALLIDAY, 1978). Os estilos variam ainda de acordo com o modo retórico, podendo ser classificados como: argumentativo, expositivo ou descritivo (FAIRCLOUGH, 2001).

A segunda dimensão diz respeito à intertextualidade manifesta, ou seja, às formas pelas quais outros textos estão explicitamente marcados na superfície textual. A intertextuali- 
dade pode acontecer de maneira normativa, com a naturalização da forma pela qual se recorre a determinados textos e convenções, mas pode, contudo, ocorrer de maneira criativa, com novas configurações de elementos de ordens do discurso e novos modos de intertextualidade manifesta (FAIRCLOUGH, 2001). As categorias eleitas neste trabalho para a observação da intertextualidade manifesta relacionam-se com a representação discursiva e com a pressuposição. A primeira categoria determina os tipos de discurso, o modo como estes estão representados e ainda a sua função no texto, por meio do entendimento do que é citado, como e por quê. A representação do discurso pode ir além do conteúdo do discurso representado, incluindo aspectos do estilo e do contexto dos enunciados representados (FAIRCLOUGH, 2001). Já as pressuposições são representadas no texto por proposições consideradas, pelos seus produtores, como algo estabelecido, sendo, portanto, uma forma de incorporar outros textos, que podem ou não ter sido produzidos pelos sujeitos envolvidos na produção do texto analisado. Segundo Fairclough (2001), as pressuposições podem ser sinceras ou manipulativas, ou seja, podem apresentar uma proposição estabelecida com o objetivo de manipulação do leitor, uma vez que proposições são freqüentemente difíceis de desafiar.

As questões propostas neste trabalho relacionam-se com o entendimento de quais textos constituem a proposta curricular de ciências para a educação de jovens e adultos, por meio de uma aproximação à dimensão da produção textual. A análise deste documento foi feita com base nas categorias que configuram a interdiscursividade e a intertextualidade manifesta, descritas anteriormente, com o objetivo de entender que discursos estão representados nesta proposta; e como estas representações discursivas implicam relações que o texto busca estabelecer com o professor de ciências, práticas de ensino e objetivos do ensino de Ciências para a EJA no segundo segmento do Ensino Fundamental.

\section{O texto e seus contextos}

De forma coerente com os princípios da Análise Crítica do Discurso, em uma análise da intertextualidade e da interdiscursividade é essencial caracterizar aspectos da historicidade dos textos. Esta caracterização permite, não só significar os textos e suas configurações em termos de estabilidades e rupturas com convenções, como discutir efeitos dos textos na sociedade e vice-versa (FAIRCLOUGH, 2001). Por esta razão, nossas análises foram informadas por leituras acerca de transformações sociais e educacionais na sociedade brasileira, bem como pela inspeção de conjunto de textos e contextos potencialmente relevantes para dar sentido aos textos das propostas curriculares de ciências para EJA.

\section{Educação em ciências: da formação do cientista à formação do cidadão}

A introdução do ensino de Ciências na escola ocorreu no início do século XX (CANAVARRO, apud NARDI e ALMEIDA, 2004), mas foi, sobretudo após a Segunda Guerra Mundial, que a disciplina ciências naturais adquiriu importância e passou a ser alvo de projetos 
Educação em Ciências e Educação de Jovens e Adultos: ...

educacionais em vários países. As mudanças ocorridas no período pós-guerra, como a profissionalização da ciência, a crescente industrialização e o desenvolvimento tecnológico e científico, não puderam deixar de impactar o currículo escolar (KRASILCHIK, 1987), que passou a responder a uma nova demanda: a formação do futuro cientista. O Brasil acompanhou esta tendência, e o ensino de Ciências passou a ter aqui um caráter propedêutico, cujo principal objetivo era a formação de uma elite de cientistas que libertariam o país da dependência estrangeira e impulsionariam o desenvolvimento científico-tecnológico (KRASILCHIK, 2000). Entretanto, os programas oficiais eram fortemente influenciados pela literatura européia e norte-americana, e os materiais educativos, muitas vezes, representavam meras traduções dos textos oriundos destes países (KRASILCHIK, 1987). Em resposta à inadequação destes textos à realidade brasileira, surgem os primeiros projetos institucionalizados de EC no Brasil, com a criação do Instituto Brasileiro de Educação, Ciência e Cultura (IBECC). Estes projetos tinham por objetivo a atualização dos conteúdos ensinados e a elaboração de materiais para aulas práticas. Segundo Krasilchik (1987), estas iniciativas pouco influenciaram as políticas públicas da educação nacional, e o período foi marcado pelo caráter memorístico do ensino de teorias e fórmulas, enfatizando somente o produto das ciências, sem problematizar as questões econômicas, políticas e sociais relacionadas ao desenvolvimento da ciência e da tecnologia.

$\mathrm{Na}$ década de 1960, a Lei de Diretrizes e Bases da Educação, promulgada em dezembro de 1961, representa uma mudança na concepção de educação, uma vez que o acesso à escola é ampliado a todos os cidadãos em idade escolar (KRASILCHIK, 2000). Segundo a autora, nesse momento é criada uma nova função para o ensino de ciências: o desenvolvimento de um espírito crítico por meio da apreensão do método científico, uma vez que os sujeitos do processo passam a ser homens comuns. Os objetivos do ensino de Ciências voltaram-se, desta forma, para o desenvolvimento de uma postura investigativa, que possibilitasse a resolução de problemas. Nesse período, foram ainda formados os Centros de Ciências, que atuaram na elaboração e implementação de currículos, materiais e recursos audiovisuais, atuando entre os anos de 1963 a 1965.

No período do regime militar, a educação brasileira passa por novas mudanças, e seus objetivos voltam-se agora para a formação do trabalhador, contribuindo para o plano de desenvolvimento econômico do país (KRASILCHIK, 2000). Estas alterações foram legitimadas pela Lei de Diretrizes e Bases da Educação de 1971, e as conseqüências para o ensino de Ciências foram significativas, uma vez que este passa a ter um caráter profissionalizante (KRASILCHIK, 2000).

\section{Alfabetização científica e movimento Ciência, Tecnologia e Sociedade (CTS)}

Durante a década de 1970, temas como ética, degradação ambiental, qualidade de vida e as implicações sociais da produção científica e tecnológica passam a integrar as discussões sobre os caminhos da ciência em nossa sociedade, refletindo um processo histórico em que se configura uma economia globalizada e o aumento das desigualdades entre países centrais e periféricos. A noção de que o desenvolvimento da ciência e da tecnologia leva ao 
desenvolvimento social passa a ser questionada, e, conseqüentemente, os objetivos do ensino de Ciências são revisitados, no sentido de responder a uma demanda por um ensino que contemple as questões e implicações sociais da ciência.

Durante a década de 1980, firmou-se um compromisso internacional entre diversos países membros da Unesco que tinha como meta a democratização do acesso ao conhecimento científico sob o lema "Ciência para Todos" (CAZELLI e FRANCO, 2001). Segundo os autores, nesse momento surge o desafio de se pensar em currículos que levem as questões anteriormente mencionadas em consideração e, para tanto, diferentes abordagens vêm sendo testadas para atingir este fim: tornar os educandos cientificamente alfabetizados. Após a abertura política, em 1996, é promulgada a Lei de Diretrizes e Bases vigente nos dias atuais. Os objetivos da educação no país são novamente revistos, cabendo agora à escola a responsabilidade de formar o cidadão-trabalhador. Nesse período são propostos, pelo Ministério da Educação, documentos de abrangência nacional contendo recomendações para o desenvolvimento de currículos, representados sobretudo pelos Parâmetros Curriculares Nacionais (PCN).

O ensino de Ciências passa, portanto, a ser marcado por objetivos de ensino voltados para a formação do cidadão, e pelo desenvolvimento de atividades com implicação social, por meio de recomendações que valorizam a contextualização e a integração entre as disciplinas.

Segundo Pella et al. (apud LAUGKSCH, 2000), um indivíduo cientificamente alfabetizado caracteriza-se por entender as inter-relações entre ciência e sociedade, a ética que rege a produção científica, a natureza da ciência, as diferenças entre ciência e tecnologia, conceitos básicos da ciência e as inter-relações entre a ciência e as humanidades. Neste sentido, o indivíduo letrado cientificamente seria capaz de desenvolver habilidades que o permitiriam utilizar conceitos científicos para a tomada de decisões responsáveis sobre sua própria vida (FOUREZ apud PFUETZENREITER, 2001).

De acordo com Shen (1975 apud DELIZOICOV e LORENZETTI, 2001), podemos distinguir três tipos de alfabetização científica, que diferem em seus objetivos, público e meios de disseminação. $O$ primeiro tipo, denominado alfabetização científica prática, serve aos propósitos de contribuir para a superação de problemas práticos do cotidiano, especialmente àqueles presentes em populações pobres. O segundo tipo, chamado de alfabetização científica cívica, relaciona-se à informação dos sujeitos sobre as questões relativas à ciência, o que permitiria uma participação mais efetiva da população e seus representantes na tomada de decisões que envolvessem questões relacionadas à ciência e à tecnologia. Já a alfabetização científica cultural relaciona-se com um desejo de um pequeno grupo de não-especialistas de buscar o entendimento da produção científica enquanto empreendimento humano. Este tipo de alfabetização não está relacionado diretamente com a tomada de decisões ou com a resolução de problemas, e sim com uma ampliação da visão de mundo daqueles que se interessam por assuntos científicos.

A alfabetização científica representa atualmente um dos principais objetivos do ensino de Ciências, com ampla produção acadêmica sobre o assunto. No campo do currículo, muitos trabalhos vêm sendo publicados no Brasil, destacando as potencialidades de currículos com ênfase nas questões que relacionam ciência, tecnologia e sociedade. Tais currículos diferenciam-se significativamente dos convencionais, pois se preocupam com a formação de atitudes e valores, são organizados em temas, em contraposição aos extensos programas tradicionalmente oferecidos, e valorizam as opiniões dos estudantes (SANTOS e MORTI- 
MER, 2000). A abordagem em temas, segundo Auler (2003), reflete a preocupação com os objetivos do ensino de Ciências, e permite a instrumentalização do aluno para sua maior compreensão e atuação na sociedade contemporânea. Neste trabalho, o autor destaca ainda a influência de Paulo Freire e Synders na dimensão ontológica desta abordagem do ensino, entendida como problematizadora e feita em sintonia com as crenças e contradições dos alunos (AULER e DELIZOICOV, 2001). Segundo Muenchen (2005), a alfabetização científica pode contribuir com o desenvolvimento da leitura crítica da realidade proposta por Paulo Freire, ao questionar pressuposições como a neutralidade da ciência e o determinismo tecnológico. Auler et al. (2005) destacam ainda que o pensamento deste educador vem contribuindo para a elaboração de currículos de ciências "mais sensíveis ao entorno, mais abertos à problemáticas contemporâneas fortemente marcadas pela dimensão científico-tecnológica" (AULER et al., 2005, p. 2).

\section{A constituição da educação de jovens e adultos como campo pedagógico}

A educação de jovens e adultos, em seu sentido mais amplo, compreende os mais diversos processos de formação - continuada e permanente, formais e informais -, perpassando quase todos os espaços de convívio social. Entretanto, as preocupações com a escolarização básica têm sido centrais no pensamento da EJA, dada a grande dívida social que existe com a população que não teve acesso à escola: até 1996, 66,2\% dos brasileiros com mais de quinze anos de idade não haviam concluído o Ensino Fundamental (DI PIERRO, JOIA e RIBEIRO, 2001).

Segundo Haddad e Di Pierro (2000), foi sobretudo na segunda metade do século XX que a educação de jovens e adultos adquiriu sua própria identidade. A primeira proposta oficial para a educação de jovens e adultos foi realizada em 1947, por meio da Campanha para Educação de Adolescentes e Adultos (CEAA) que, apesar de apresentar uma proposta mais ampla de educação, teve suas ações somente voltadas para a alfabetização e para ações de educação sanitária (FÁVERO, 2004). A CEEA, que durou até o final da década de 1950, atendia sobretudo ao objetivo de prover qualificações mínimas à força de trabalho, condição necessária para que o país desenvolvesse o seu plano de desenvolvimento (HADDAD e DI PIERRO, 2000).

As campanhas que se seguiram na década de 1960, interrompidas pelo golpe militar, também foram voltadas para a alfabetização, com as propostas de leitura de mundo de Paulo Freire e o Movimento de Cultura Popular, os Centros Populares de Cultura e outros. Os movimentos de educação popular representaram uma grande influência para a construção da identidade da educação de jovens e adultos, especialmente a pedagogia de Paulo Freire, baseada no diálogo e voltada para a formação política e para a transformação social (RIBEIRO, 1999). Durante o regime militar, programas nacionais como a Cruzada ABC (Ação Básica Cristã), extinta em 1971, e o MOBRAL (Movimento Brasileiro de Alfabetização) foram criados para suprir as lacunas deixadas pela repressão aos movimentos de educação popular. $\mathrm{O}$ MOBRAL representou uma campanha de massa, com objetivo de sanar o problema do analfabetismo e ainda realizar uma ação ideológica que mantivesse a situação política vigente 
(HADDAD e DI PIERRO, 2000). Com a abertura política e com a evidente ineficiência do programa, o MOBRAL foi extinto em 1985 (DI PIERRO, JOIA e RIBEIRO, 2001).

A Constituição Brasileira de 1988, influenciada pela revitalização dos pensamentos e práticas dos grupos de educação popular reprimidos pelo regime militar, estabelece o direito à educação de jovens e adultos, quando expressa a garantia de Ensino Fundamental, obrigatório e gratuito para cidadãos em qualquer idade. Esse período foi marcado pelo fortalecimento dos cursos supletivos por meio da criação da Fundação Nacional para Educação de Jovens e Adultos - Educar, e após a sua extinção, em 1990, pela descentralização dos projetos de EJA, que ficaram a cargo dos estados e municípios (HADDAD e DI PIERRO, 2000).

A LDB 9.394/96, nos artigos que dizem respeito especificamente à educação de jovens e adultos, incorpora uma mudança conceitual, onde o ensino supletivo foi substituído pela educação em um sentido mais amplo, compreendendo os diversos processos de formação (SOARES, 2002). Segundo Paiva (2004), as novas construções da realidade brasileira passam a ser incorporadas ao aparato legal. Estas construções podem ser associadas à reivindicação dos direitos pelos jovens e adultos excluídos do sistema educacional, e se dão num contexto de articulação das diversas iniciativas ligadas à EJA com objetivo de representação do país na V CONFITEA (Conferência Internacional de Educação de Adultos - UNESCO, 1998), realizada em Hamburgo, em 1997. Estas iniciativas envolveram mapeamentos das instituições e das ações desenvolvidas na EJA em âmbito estadual, regional e nacional. A articulação impulsionada pela V CONFITEA teve continuidade com a formação dos fóruns estaduais de EJA e com a realização de encontros anuais que discutem esta modalidade da educação. Segundo Soares (2002), as ações desenvolvidas pelos fóruns e encontros contribuíram diretamente com a elaboração das Diretrizes Curriculares Nacionais para a EJA, uma vez que foi possível ler, discutir e ver incorporadas as contribuições às muitas versões do documento.

O parecer CEB 11/2000 (BRASIL, 2000), que estabelece as Diretrizes Curriculares Nacionais para a educação de jovens e adultos e pode ser considerado o principal documento regulamentador e normatizador para este segmento da educação, define a EJA como modalidade da educação básica e como direito do cidadão. Mais que normatizar e regulamentar, este documento pode ser considerado um marco, uma vez que supera a concepção de suplência e aligeiramento do ensino, amplamente utilizada e difundida até poucos anos atrás, e legitima o direito por uma educação de qualidade. As Diretrizes Curriculares Nacionais para a educação de jovens e adultos conceituam este segmento como "uma categoria organizacional constante da estrutura da educação nacional, com finalidades e funções específicas" (BRASIL, 2000, p. 5).

Nesse documento são estabelecidas, portanto, as funções reparadora, equalizadora e qualificadora da EJA. A primeira relaciona-se com a concepção de que o estudante da EJA teve o direito à educação negado, e que este deve ser restaurado. A segunda relaciona-se com a promoção de oportunidades que levem a uma condição igualitária na sociedade, e a última, com o direito de aprender por toda a vida. Neste sentido, as finalidades da EJA vão além dos processos iniciais de alfabetização, buscando formar indivíduos capazes de se apropriar das múltiplas linguagens presentes na sociedade, e de estabelecer um diálogo entre estas e suas experiências de vida e de trabalho. As Diretrizes Curriculares Nacionais para a EJA estabelecem, desta forma, o currículo em duas partes: uma base nacional comum, que garanta a integração, e outra parte, diversificada, que garanta a contextualização. 
Educação em Ciências e Educação de Jovens e Adultos: ...

Nesse momento cria-se, portanto, uma nova demanda para as diferentes disciplinas, que devem pensar sobre como a formação de professores, os currículos e os materiais educativos podem contemplar as necessidades dos educandos da EJA. Nesse cenário de significativas mudanças - conceituais e legais - é elaborada a proposta curricular do MEC para a educação de jovens e adultos, que analisamos neste trabalho.

\section{Recorte da pesquisa, definição do corpus e análises}

A proposta curricular para a EJA (BRASIL, 2002) é organizada em três volumes. O primeiro, introdutório aos dois subseqüentes, discute algumas especificidades da EJA e a elaboração de propostas curriculares que atendam a estas características. Os demais volumes compreendem abordagens específicas às disciplinas, e contam com uma introdução e com seções referentes aos objetivos, conteúdos, orientações didáticas e avaliação. A escolha da seção introdutória do material de ciências foi realizada porque esta representa uma síntese do material como um todo, no que diz respeito aos critérios para seleção de conteúdos, às orientações didáticas e aos objetivos do ensino de Ciências para a modalidade de jovens e adultos. Neste sentido, as orientações contidas no trecho selecionado para as análises podem ser reconhecidas no restante do documento, podendo ser consideradas como representativas da proposta. Além disso, a escolha deste trecho para análise relaciona-se com a citação do documento síntese da V CONFITEA (UNESCO, 1998), permitindo, desta forma, uma aproximação à intertextualidade manifesta ao diálogo entre os campos que se busca construir no texto. É importante ressaltar ainda que esta publicação foi feita quatro anos após o lançamento dos Parâmetros Curriculares Nacionais (PCN), e que o quadro institucional e a coordenação geral de ambos os projetos foi semelhante. Desta forma, o documento surge como uma forma de organizar as propostas para a EJA de maneira coerente com aquelas contidas nos PCN.

A análise que se segue será apresentada tendo como referência segmentos extraídos da introdução ao capítulo Ciências Naturais na Educação de Jovens e Adultos (BRASIL, 2002), contido no volume três da proposta curricular para o segundo segmento do Ensino Fundamental. Neste volume estão ainda as propostas para matemática, arte e educação física. Estes trechos, transcritos abaixo, são seqüenciais no texto e foram selecionados porque ilustram a questão dos objetivos, da seleção de conteúdos e as orientações didáticas para o ensino de Ciências na educação de jovens e adultos.

\section{Segmento 1:}

1 As rápidas mudanças na sociedade e no mundo atual guardam intrincadas relações com

2 as crescentes produções científicas e tecnológicas. Essas relações - históricas, políticas

3 e culturais - determinam a qualidade de vida dos povos e os instrumentos de sua

4 consciência crítica.

\section{Segmento 2:}

Elas são parte do debate democrático por um mundo mais justo, voltado para o desenvolvimento sustentado, para a superação das desigualdades, para a dignidade e a solidariedade. A tarefa de conhecer as relações entre ciência, tecnologia e sociedade inscreve-se no processo de educação permanente, do qual também faz parte o aprimoramento de habilidades e valores. 
Vilanova, R.; Martins, I.

\section{Segmento 2:}

10 Com base em considerações dessa natureza, as leis vigentes preconizam a integração entre

11 a Educação de Jovens e Adultos (EJA) e a vida cidadã, de modo que cada componente

12 curricular contribua com uma melhor orientação para o trabalho e com a ampliação dos

13 significados das experiências de vida dos alunos.

\section{Segmento 3:}

14 Eles devem ter acesso aos conhecimentos que poderão promover e ampliar suas

15 interpretações sobre aspectos individuais e coletivos que condicionam a saúde e a

16 reprodução humanas, sobre as transformações dos ecossistemas no planeta como um todo

17 - e particularmente no lugar onde vivem. Questões como essas pautam a formulação desta

18 proposta para o currículo de ciências naturais.

\section{Segmento 4:}

19 Estreitamente ligadas à meta do desenvolvimento sustentável e firmadas como

20 compromissos da $5^{a}$ Conferência Internacional sobre Educação de Adultos (Confitea), tais

21 questões contribuíram para a redefinição das discussões acumuladas no marco dos

22 Parâmetros Curriculares Nacionais. Debatidas na $5^{a}$ Confitea, resultaram em diversos

23 compromissos, entre os quais se destacam os relacionados a seguir:

24 - Promover a capacidade e a participação da sociedade civil em responder e

25 buscar soluções para os problemas do meio ambiente e de desenvolvimento.

26 - Estimular o aprendizado dos adultos em matéria de população e vida

27 familiar.

28 - Reconhecer o papel decisivo da educação sanitária na preservação e

29 melhoria da saúde pública e individual.

30 - Assegurar a oferta de programas de educação adaptados à cultura local e

31 às necessidades específicas, no que se refere à atividade sexual.

\section{Segmento 5:}

32 Diante dessas demandas, conteúdos e métodos habituais em ciências naturais devem

33 ser revistos criticamente na elaboração e consecução dos projetos educativos.

\section{Segmento 6:}

34 É necessário rever a prioridade que se dá às meras descrições dos fenômenos naturais e à 35 transmissão de definições, regras e fórmulas - muitas vezes sem estabelecer vínculos com 36 a realidade do estudante ou outros contextos que tornariam o conhecimento científico mais 37 interessante, instigante e útil [...].

\section{Segmento 7:}

38 O acesso às ciências naturais em EJA deve se dar juntamente com a promoção da 39 racionalidade, a confirmação de competências adquiridas na vida extra-escolar e $o$ 40 banimento do medo e dos preconceitos." 
Educação em Ciências e Educação de Jovens e Adultos: ...

\section{Discussão}

A análise da interdiscursividade possui como principal objetivo o delineamento dos discursos presentes na amostra (FAIRCLOUGH, 2001). No texto analisado, a amostra pôde ser caracterizada como uma introdução típica de uma proposta educacional (Segmentos 1 e 2: linhas 1 a 9), iniciando-se com uma contextualização que se relaciona com a justificativa das escolhas de abordagens e temas. O estilo pôde ser especificado como tenor formal, por exemplo, pelo uso de termos como "preconizam" - Segmento 2: linha 10 e "consecução" Segmento 5: linha 33, modo "escrito para ser lido" (uso de aposto na Sentença 1: linha 3). O modo retórico, argumentativo, pode ser ilustrado pela utilização dos verbos dever - Segmento 5: linha 32 e rever - Segmento 6: linha 34, e pela utilização de termos como "demandas" (Segmento 5: linha 32) e "necessário" (Segmento 6: linha 34). A natureza do documento relaciona-se diretamente com a questão do estilo, uma vez que se trata de um documento oficial, o qual espera-se que seja consultado pelas equipes pedagógicas e pelos professores, o que acarreta o tenor formal e o modo "escrito para ser lido". O modo retórico, argumentativo, torna-se óbvio por se tratar de uma proposta que, como tal, busca convencer os leitores de que é apropriada e coerente com as necessidades da EJA.

Já os objetivos da análise da intertextualidade manifesta relacionam-se com a especificação dos textos que estão constituindo a amostra, e como isso ocorre (FAIRCLOUGH, 2001). No trecho que analisamos, podemos identificar tanto o discurso da EJA como o da Educação em Ciências como representados. O primeiro no Segmento 2 (linhas 10 a 13), que menciona orientação para o trabalho, e o segundo, que se constrói com base nos parâmetros curriculares nacionais, por meio de referência no Segmento 7 (linhas 38 a 40): a questão do desenvolvimento de competências pode ser considerada uma marca no discurso dos PCN. As pressuposições podem ser exemplificadas no Segmento 5 , em que assume-se que as demandas mencionadas podem ser supridas caso as recomendações da proposta sejam seguidas.

O Segmento 4 articula duas representações de discurso, o da EJA e o referente ao Educação em Ciências que se constrói nos Parâmetros Curriculares Nacionais. A questão do desenvolvimento sustentado é discutida na Declaração de Hamburgo e nos PCN, entretanto, em nenhum dos documentos a questão é encarada como uma meta que pode ser alcançada por meio da educação, como pressupõe o documento em análise, o que caracteriza uma formulação criativa. A proposta resgata os compromissos estabelecidos na V CONFITEA (UNESCO, 1998) que podem ser relacionados com as questões de saúde e meio ambiente, presentes no tema seis deste documento, intitulado "A educação de adultos em relação ao meio ambiente, a saúde e a população". É importante ressaltar que nem todos os compromissos firmados dentro deste tema foram representados na proposta curricular para a EJA (os compromissos referentes à propriedade intelectual e ao apoio a bibliotecas e instituições culturais não aparecem no documento analisado), provavelmente porque não estão diretamente relacionados ao ensino de Ciências. Isto sugere uma contradição no texto, uma vez que este valoriza a ampliação de significados das experiências de vida e o acesso a conhecimentos, mas, ao suprimir estes compromissos, assume que estes não representam atribuições do ensino de Ciências.

A representação do discurso dos PCN pode ser observada no Segmento 4, quando os mesmos são encarados como um marco na educação e quando a referência às discussões 
(mas não especificamente às críticas) que resultaram nos compromissos citados é feita de maneira inespecífica, o que pressupõe a valorização deste documento como referência para a elaboração da proposta para a EJA.

Os Segmentos 6 e 7 delineiam o discurso referente aos Parâmetros Curriculares Nacionais, quando reproduzem as críticas relacionadas a questões como o ensino descontextualizado e fragmentado, e destacam a importância de tornar o conhecimento mais interessante, instigante ou útil. Apesar de estas discussões serem anteriores aos PCN, podemos notar que o estilo e a estrutura do texto são semelhantes nos dois documentos, o que remete ao texto dos PCN como referência. No Segmento 7 é possível observar uma articulação interessante entre o discurso da EJA e o dos PCN. O documento referente à EJA trata a questão das competências como algo a ser confirmado a partir da vida extra-escolar. Nota-se, portanto, uma adaptação aos PCN, que se referem ao desenvolvimento de competências pelos estudantes. Desta forma, o termo "confirmado" relaciona-se com a valorização da experiência de vida trazida pelo estudante jovem e adulto para o contexto da sala de aula.

Com base nestas análises podemos reconhecer o documento da proposta curricular de Ciências para a EJA como parte integrante do projeto de educação que tem como marcos fundadores a Lei de Diretrizes e Bases da Educação Nacional de 1996 e os Parâmetros Curriculares Nacionais. A análise da intertextualidade nos mostra que o estabelecimento do diálogo entre o discurso que fundamenta este projeto de educação e o discurso da EJA se dá por meio do estabelecimento de relações entre a proposta instrumentalizadora dos Parâmetros Curriculares Nacionais e os compromissos firmados na V CONFITEA (UNESCO, 1998).

Este diálogo, que pode ser observado em especial nos Segmentos 4 e 7, caracteriza dois enunciados principais: o primeiro remete à formação para a cidadania - educação para a participação na sociedade civil (Segmento 4: linhas 24 e 25) e promoção da racionalidade (Segmento 7: linhas 39 e 40). O segundo, no entanto, afilia-se a um discurso que coloca o adulto como objeto de medidas de educação sanitária (Segmento 4: linhas 26 a 31), por meio da confirmação de competências adquiridas na vida extra-escolar (Segmento 7: linha 39). Este enunciado, a nosso ver, estabelece uma relação bastante assimétrica com o conhecimento e as possibilidades de participação na esfera pública associadas a este, representando, desta maneira, uma contradição no texto.

\section{Conclusões}

Durante as últimas décadas, a educação brasileira passou por diversas modificações, precisando sempre responder aos diferentes momentos políticos vividos. O primeiro, e talvez o principal distanciamento entre os campos da EJA e do EC pode ser observado no período considerado fundador do pensamento atual sobre estas áreas do ensino no país. É na década de 1950 que o ensino de Ciências e a educação de jovens e adultos passam a ser considerados importantes para o desenvolvimento econômico e social do Brasil e, também, a ser alvos de programas e reformas educacionais governamentais. Neste sentido, o discurso sobre os objetivos do ensino de Ciências é declaradamente o da formação de elites, enquanto o da educação de jovens e adultos é aquele da alfabetização para a formação de mão-de-obra melhor qualificada. Com a democratização do ensino, os objetivos do ensino de Ciências passam a 
enfatizar a formação de uma postura crítica em relação à ciência pelos estudantes. Entretanto, a implementação de currículos que efetivamente promovam a alfabetização científica dos educandos depende de profundas mudanças no paradigma educacional em nosso país. De acordo com Delizoicov, Angotti e Pernambuco (2002), o objetivo de formar cientistas ainda é fortemente presente no ensino de Ciências. Segundo Krasilchik (1987), apesar de a lei e os profissionais da área defenderem os objetivos da formação em ciências para um pleno exercício da cidadania, o sistema educacional e a realidade da sala de aula não vão de encontro a estes objetivos, incoerência esta que dificulta a implementação de propostas que efetivamente transformem a educação científica.

Historicamente, a EJA tem voltado seus esforços institucionais e investimentos para projetos de alfabetização. Aos adultos alfabetizados que buscavam continuidade dos seus estudos, restava a busca por cursos supletivos, que de maneira geral representavam adaptações malfeitas dos cursos regulares, infantilizando os alunos e utilizando materiais educativos repletos de erros conceituais.

Com as mudanças na Constituição de 1988, que legitimam o direito à Educação Básica para os indivíduos em qualquer idade, e com a Lei de Diretrizes e Bases da Educação Nacional, que, em 1996, passa a assegurar o direito a uma educação plena aos jovens e adultos, o ensino das disciplinas passa a demandar a elaboração de projetos pedagógicos que atendam às especificidades dos estudantes da EJA. A literatura e os profissionais especializados em ensino de Ciências para esta modalidade são, entretanto, escassos. Esta carência implica a necessidade de adaptações de propostas, materiais educativos e metodologias de ensino criadas para atender aos objetivos do Ensino Regular. Nestas adaptações buscam-se articulações entre o discurso da EJA e o da Educação em Ciências, conforme indica a análise da proposta curricular de ciências para a EJA elaborada pelo MEC.

Neste sentido, questões que permitiriam uma aproximação entre os campos da EJA e do ensino de ciências, como, por exemplo, a emancipação dos sujeitos e o desenvolvimento de uma visão crítica e de um posicionamento político em relação à ciência e a tecnologia, parecem se distanciar dos objetivos desta proposta. A seleção dos compromissos da V CONFITEA, citada na proposta curricular para o ensino de Ciências, reflete a ênfase que se deseja dar a conteúdos que privilegiam questões de saúde, sexualidade e problemas ambientais. As poucas iniciativas na EJA relacionadas a temas de ciências anteriores à LDB 9394/96 geralmente estavam voltadas para: educação sanitária, saúde reprodutiva, controle da natalidade, prevenção das doenças sexualmente transmissíveis e segurança alimentar. A análise do trecho do documento demonstra que esta tradição se mantém nesta proposta, o que sugere que, considerado o pouco tempo dos estudantes da EJA para dedicação aos estudos, a seleção de conteúdos e abordagens para o ensino de Ciências deve se restringir ao nível da alfabetização científica prática (SHEN, 1975, apud DELIZOICOV e LORENZETTTI, 2001)

Podemos identificar, desta forma, a questão do conhecimento útil como uma marca discursiva desta proposta, preocupada em relacionar o ensino de Ciências à promoção da saúde pública, a educação para o trabalho e para a cidadania. Entretanto, as duas últimas são mencionadas de maneira bastante inespecífica, o que pode indicar a ausência de propostas neste sentido, ou, ainda, um desinteresse institucional no desenvolvimento destas habilidades.

Esta visão se afasta da concepção de uma educação plena, que é garantida ao estudante jovem e adulto pela legislação, uma vez que apesar de os conteúdos relacionados a estes 
Vilanova, R.; Martins, I.

temas serem fundamentais para a formação do cidadão, estes representam apenas uma faceta do conhecimento científico. Neste sentido, o compromisso com uma educação plena deve buscar o equilíbrio entre os conhecimentos úteis para a vida cotidiana e aqueles que conjuntamente com estes levam a uma visão ampla das ciências e que, efetivamente, permitem uma inclusão verdadeira e completa na sociedade. Estas considerações sugerem a necessidade de um maior diálogo entre a Educação de Jovens e Adultos e a Educação em Ciências, entendidas nas suas dimensões de campos de investigação e intervenção, no sentido de problematizar objetivos e práticas e, conjuntamente, caminhar buscando superar limites e efetivar uma proposta de formação comprometida com a emancipação e participação plena dos sujeitos em sociedade.

Portanto, atingir os objetivos do ensino de Ciências na EJA não representa tarefa simples. A educação de jovens e adultos, entretanto, pode ser considerada terreno fértil para inovações práticas e teóricas (DI PIERRO, JOIA e RIBEIRO, 2001), cabendo, assim, às instituições formadoras de professores de ciências valorizarem e voltarem parte dos seus esforços para esta modalidade da educação, o que pode contribuir, em longo prazo, para a superação da concepção do ensino propedêutico e voltado para as elites, ainda muito presente na prática educativa do ensino de ciências no Brasil.

\section{Referências}

AULER, D. Alfabetização científico-tecnológica: um novo paradigma? Ensaio, v. 5, n. 1, p. 12-25, 2003.

.; DELIZOICOV, D. Alfabetização científico-tecnológica para quê? Ensaio, v. 3, n.1, p. 1-13, 2001.

et al. Compreensões de alunos da educação básica sobre interações entre CTS. In: ENCONTRO NACIONAL DE PESQUISA EM EDUCAÇÃO EM CIÊNCIAS, 5. 2005, Bauru. Anais... Bauru: ABRAPEC, 2005. 1 CD-ROM.

BAKHTIN, M. M. Os gêneros do discurso. In: ___. Estética da criação verbal. Trad. Maria Eermantina Galvão G. Pereira. 3. ed. São Paulo: Martins Fontes, 2000.

BARROS, M. F. R. et al. Tendências atuais na educação em ciências de jovens e adultos. In: ENCONTRO NACIONAL DE PESQUISA EM EDUCAÇÃO EM CIÊNCIAS, 4., 2003, Bauru. Anais... Bauru, 2003.

BRASIL. Ministério da Educação, Secretaria de Educação Fundamental. Proposta curricular para a educação de jovens e adultos: segundo segmento do Ensino Fundamental $-5^{a}$ a $8^{a}$ séries. Brasília: MEC/SEF, 2002.

BRASIL. Parecer CNE 11/2000: Diretrizes Curriculares Nacionais para a Educação de Jovens e Adultos. Brasília: Câmara de Educação Básica, 2000.

CAZELLI, S.; FRANCO, C. Alfabetismo científico: novos desafios no contexto da globalização. Ensaio, v. 3, n. 1, p. 12-25, 2001. 
Educação em Ciências e Educação de Jovens e Adultos: ...

DELIZOICOV, D.; ANGOTTI, J. A.; PERnAMBUCO, M. M. Ensino de Ciências: fundamentos e métodos. São Paulo: Cortez, 2002.

.; LORENZETTI, L. Alfabetização científica no contexto das séries iniciais.

Ensaio, v. 3, n. 1, p. 37-50, 2001.

DI PIERRO, M. C.; JOIA, O.; RIBEIRO, V. M. Visões da educação de jovens e adultos no Brasil. Cadernos Cedes, v. 21, n. 55, p. 58-77, 2001.

FAIRCLOUGH, N. Discurso e mudança social. Brasília: Universidade de Brasília, 2001.

FÁVERO, O. Lições da história: os avanços de sessenta anos e a relação com as políticas de negação de direitos que alimentam as condições de analfabetismo no Brasil. In: OLIVEIRA, I. B.; PAIVA, J. (Orgs.). Educação de jovens e adultos. Rio de Janeiro: DP\&A, 2004. p. 13-28.

FOUCAULT, M. Arqueologia do saber. Petrópolis: Vozes, 1972.

HALLIDAY, M. A. K. Language as social semiotic. Londres: Edward Arnold, 1978.

HADDAD, S.; DI PIERRO, M. C. Escolarização de jovens e adultos. Revista Brasileira de Educação, n. 14, p. 108-130, 2000.

KRASILCHIK, M. Reformas e realidade: o caso do ensino das ciências. São Paulo em Perspectiva, v. 14, n. 1, p. 85-93, 2000.

O professor e o currículo das ciências. São Paulo: Editora da Universidade de São Paulo, 1987.

KRESS, G. Linguistic processes in sociocultural practice. Oxford: Oxford University Press, 1988.

LAUGKSCH, R. Scientific literacy: a conceptual overview. Science Education, v. 84, n. 1, p. 71-94, 2000.

MARTINS, I.; NASCIMENTO, T. G. e ABREU, T. B. Clonagem na sala de aula: um exemplo do uso didático de um texto de divulgação científica. Investigações em Ensino de Ciências, v. 9, n. 1, p. 95-111, 2004.

MUENCHEN, C. Enfoque CTS: configurações curriculares sensíveis a temas contemporâneos. In: ENCONTRO NACIONAL DE PESQUISA EM ENSINO DE CIÊNCIAS, 5., 2005, Bauru. Anais... Bauru, 2005.

NARDI, R.; ALMEIDA, M. J. P. M. Formação da área de ensino de Ciências: memórias de pesquisadores no Brasil. Revista Brasileira de Pesquisa em Educação em Ciências, v. 4, n. 1, p. 90-100, 2004.

PAIVA, J. Educação de jovens e adultos: questões atuais em cenário de mudança. In: OLIVEIRA, I. B.; PAIVA, J. (Orgs.). Educação de jovens e adultos. Rio de Janeiro: DP\&A, 2004. p. 29-42. 
Vilanova, R.; Martins, I.

PFUETZENREITER, M. R. A ruptura entre o conhecimento popular e o científico em saúde. Ensaio, v. 3, n. 1, p. 44-57, 2001.

RIBEIRO, V. M. A formação de educadores e a constituição da educação de jovens e adultos como campo pedagógico. Educação \& Sociedade, v. 20, n. 68, p. 184-201, 1999.

SANTOS, W. L. P.; MORTIMER, E. F. Uma análise de pressupostos teóricos da abordagem C-T-S (Ciência-Tecnologia-Sociedade) no contexto da educação brasileira. Ensaio, v. 2, n. 2, p. 133-162, 2000.

SOARES, L. J. G. O contexto em que surgem as Diretrizes Curriculares Nacionais para EJA. In: SOARES, L. J. G. (Org.). Diretrizes Curriculares Nacionais - Educação de jovens e adultos. Rio de Janeiro: DP\&A, 2002. p. 7-24.

UNESCO. V Conferência Internacional sobre Educação de Adultos: declaração final e agenda para o futuro. Brasilia: MEC/SEF, 1998.

Artigo recebido em outubro de 2006 e aprovado em março de 2008. 